\title{
Fruits and vegetables that are sources for lutein and zeaxanthin: the macular pigment in human eyes
}

\author{
Olaf Sommerburg, Jan E E Keunen, Alan C Bird, Frederik J G M van Kuijk
}

\begin{abstract}
Background-It has been suggested that eating green leafy vegetables, which are rich in lutein and zeaxanthin, may decrease the risk for age related macular degeneration. The goal of this study was to analyse various fruits and vegetables to establish which ones contain lutein and/or zeaxanthin and can serve as possible dietary supplements for these carotenoids.

Methods-Homogenates of 33 fruits and vegetables, two fruit juices, and egg yolk were used for extraction of the carotenoids with hexane. Measurement of the different carotenoids and their isomers was carried out by high performance liquid chromatography using a single column with an isocratic run, and a diode array detector. Results-Egg yolk and maize (corn) contained the highest mole percentage $(\%$ of total) of lutein and zeaxanthin (more than $85 \%$ of the total carotenoids). Maize was the vegetable with the highest quantity of lutein $(60 \%$ of total) and orange pepper was the vegetable with the highest amount of zeaxanthin (37\% of total). Substantial amounts of lutein and zeaxanthin (30$50 \%$ ) were also present in kiwi fruit, grapes, spinach, orange juice, zucchini (or vegetable marrow), and different kinds of squash. The results show that there are fruits and vegetables of various colours with a relatively high content of lutein and zeaxanthin.

Conclusions-Most of the dark green leafy vegetables, previously recommended for a higher intake of lutein and zeaxanthin, have $15-47 \%$ of lutein, but a very low content $(0-3 \%)$ of zeaxanthin. Our study shows that fruits and vegetables of various colours can be consumed to increase dietary intake of lutein and zeaxanthin. (Br f Ophthalmol 1998;82:907-910)
\end{abstract}

The two major carotenoids in the human macula and retina are lutein and zeaxanthin, ${ }^{1}{ }^{2}$ and they are often referred to as xanthophylls, or macular pigment. Handelman et al ${ }^{1}$ found a fivefold higher content of these carotenoids in the macula compared with the peripheral retina. Snodderly et $a l^{3}$ reported that macaque monkeys, which have foveal cone types like the human retina, have a consistent pattern of more zeaxanthin than lutein in the foveal centre. In the periphery zeaxanthin declines more rapidly than lutein, so that lutein becomes dominant. $^{2}$ The carotenoids are thought to function as antioxidants and/or as a blue light filter, to protect the underlying tissues from phototoxic damage. ${ }^{4}$ This has been proposed as a factor, especially in the pathophysiology of age related macular degeneration (ARMD). ${ }^{6}$ Hammond et $a l^{7}$ found a correlation between macular pigment density and iris colour, and suggested a correlation between dietary carotenoid intake and macular pigment density. Such a correlation was demonstrated in two subjects by Landrum et $a l^{8}$ and in a larger group by Hammond et al. ${ }^{9}$

In recent years several epidemiological studies reported the inverse correlation between micronutrients in plasma and the risk of certain eye disorders thought to be related to free radical generation. Jacques et all ${ }^{10}$ suggested a relation between intake of antioxidant vitamins and carotenoids and the prevention of cataract. In 1993 the Case Control Study Group for Eye Diseases of the United States evaluated the relation between a decreased plasma level of lutein and zeaxanthin and the risk of the exudative form of neovascular ARMD.${ }^{11}$ Seddon et al reported the results of further investigations from the Case Control Study Group for Eye Diseases, which showed that a high dietary intake of carotenoids, in particularly those in dark green leafy vegetables, was associated with a $43 \%$ lower risk for ARMD. ${ }^{12}$ West et $a l^{13}$ suggested a protective effect of high plasma $\alpha$ tocopherol values of ARMD, and demonstrated a correlation between ARMD and an antioxidant index consisting of ascorbic acid, $\alpha$ tocopherol, and $\beta$ carotene. In 1995 Mares-Perlman et al ${ }^{14}$ reported that a low plasma level of lycopene was associated with ARMD. The role of carotenoids in protection from ARMD was discussed in reviews by Snodderly ${ }^{15}$ and Landrum et al. ${ }^{16}$

Fruits and vegetables are the most important source of carotenoids in the human diet, and knowledge about this is important for preventive medicine. Several publications report the qualitative and quantitative content of carotenoids in different fruits and vegetables. ${ }^{17-21}$ However, many of the procedures used did not allow the separation of lutein and zeaxanthin, and they are typically reported as a single group. To date, there is no comprehensive information on the separate content of lutein and zeaxanthin in fruits and vegetables. Since the macular pigments are not evenly distributed throughout the human retina, ${ }^{12}$ knowledge about this may be valuable. The goal of our study was to analyse a number of fruits and vegetables for the content of each macular pigment. This may help to give guidelines as to 
which food products can help decrease the risk of cataract and ARMD.

\section{Methods}

SOURCES OF CAROTENOID STANDARDS

Apo-10'-carotenal and zeaxanthin were a generous gift by Hoffmann-La Roche, Nutley, NJ, USA. Lutein, $\beta$ carotene, and $O$-ethylhydroxylamine were purchased from Fluka, Ronkonkoma, NY, USA. Apo-10'-carotenalmethyl oxime was used as internal standard, and was synthesised as described elsewhere. ${ }^{22}$

\section{SAMPLE PREPARATION}

For the extraction procedure a $5 \mathrm{~g}$ piece of fruit or vegetable was used. The tissue was homogenised with a pestle in a mortar containing $1 \mathrm{ml}$ of phosphate buffered saline (PBS) $(10 \mathrm{mM}$ $\mathrm{NaH}_{2} \mathrm{PO}_{4}$, water with $0.15 \mathrm{~N} \mathrm{NaCl}$ titrated to $\mathrm{pH}$ 4.7). Sodium sulphate and sodium chloride were from Fisher Scientific, Fair Lawn, NJ, USA. The homogenate was transferred to a 7 $\mathrm{ml}$ vial and $1 \mathrm{ml}$ of methanol, containing butylated hydroxytoluene $(0.5 \mathrm{mg} / \mathrm{ml})$ (BHT Sigma Chemical Co, St Louis, MO, USA). BHT was added before mixing the sample for 30 seconds. Ethanol was from Midwest Grain Products Co, Weston, MI, USA. For fruit juices and egg yolk, $2 \mathrm{ml}$ was mixed with $1 \mathrm{ml}$ methanol BHT $(0.5 \mathrm{mg} / \mathrm{ml})$. To extract the carotenoids from the samples, $2 \mathrm{ml}$ of hexane and $1 \mathrm{ml}$ of hexane containing the internal standard was added to the samples, and they were vortexed for 3 minutes, and centrifuged at $1800 \times g$ for 3 minutes. The upper layer of the sample containing the carotenoids was collected and passed through a Pasteur pipette, prepared with $\sim 150 \mathrm{~g}$ of anhydrous sodium sulphate to remove any traces of moisture. The hexane extraction was repeated once with $2 \mathrm{ml}$ of hexane. The extracted carotenoids in hexane are stable for several weeks at $-20^{\circ} \mathrm{C}$. Since the amount of extracted carotenoids was different for each of the fruits and vegetables the absorbance of $1 \mathrm{ml}$ of the obtained hexane phase was measured in a Shimadzu Spectrophotometer UV-2101PC. To detect the carotenoids by high performance liquid chromatography (HPLC), a certain volume of the hexane phase $(100 \mu \mathrm{l}-1 \mathrm{ml})$, corresponding to an optical density of 0.3 , was evaporated under a steam of argon. The residue was redissolved in $60 \mu \mathrm{l}$ methanol and $20 \mu \mathrm{l}$ was injected on the HPLC.

HIGH PERFORMANCE LIQUID CHROMATOGRAPHY The HPLC consisted of a Beckman System Gold Programmable Solvent Module 125 (Beckman Instruments Inc, Palo Alto, CA, USA), a Beckman System Gold Diode Array Detector Module 168, and a Rheodyne 7725i Injector valve with a $20 \mu \mathrm{l}$ injection loop (Rheodyne Inc, Cotati, CA, USA). The diode array detector was set in channel $\mathrm{A}$ at wavelength $450 \mathrm{~nm}$ to detect the carotenoids. The second channel $\mathrm{B}$ was set at $300 \mathrm{~nm}$ to detect retinols and tocopherols. A reverse phase $5 \mu \mathrm{m}_{18}$ column, $250 \times 4.6 \mathrm{~mm}$ (VYDAC, 218TP54, Hesperia, CA, USA), with a precolumn $(40 \times 4.6 \mathrm{~mm})$ was used. For

Table 1 Carotenoids in fruits and vegetables

\begin{tabular}{|c|c|c|c|c|c|c|c|c|}
\hline & $\begin{array}{l}\text { Neoxanthins and } \\
\text { violaxanthins }\end{array}$ & $\begin{array}{l}\text { Lutein and } \\
\text { zeaxanthin }\end{array}$ & Lutein & Zeaxanthin & Cryptoxanthins & Lycopenes & a carotene & $\beta$ carotene \\
\hline Egg yolk & 8 & 89 & 54 & 35 & 4 & 0 & 0 & 0 \\
\hline Maize (corn) & 9 & 86 & 60 & 25 & 5 & 0 & 0 & 0 \\
\hline Kiwi & 38 & 54 & 54 & 0 & 0 & 0 & 0 & 8 \\
\hline Red seedless grapes & 23 & 53 & 43 & 10 & 4 & 5 & 3 & 16 \\
\hline Zucchini squash & 19 & 52 & 47 & 5 & 24 & 0 & 0 & 5 \\
\hline Pumpkin & 30 & 49 & 49 & 0 & 0 & 0 & 0 & 21 \\
\hline Spinach & 14 & 47 & 47 & 0 & 19 & 4 & 0 & 16 \\
\hline Orange pepper & 4 & 45 & 8 & 37 & 22 & 0 & 8 & 21 \\
\hline Yellow squash & 19 & 44 & 44 & 0 & 0 & 0 & 28 & 9 \\
\hline Cucumber & 16 & 42 & 38 & 4 & 38 & 0 & 0 & 4 \\
\hline Pea & 33 & 41 & 41 & 0 & 21 & 0 & 0 & 5 \\
\hline Green pepper & 29 & 39 & 36 & 3 & 20 & 0 & 0 & 12 \\
\hline Red grape & 27 & 37 & 33 & 4 & 29 & 0 & 1 & 6 \\
\hline Butternut squash & 24 & 37 & 37 & 0 & 34 & 0 & 5 & 0 \\
\hline Orange juice & 28 & 35 & 15 & 20 & 25 & 0 & 3 & 8 \\
\hline Honeydew & 18 & 35 & 17 & 18 & 0 & 0 & 0 & 48 \\
\hline Celery (stalks, leaves) & 12 & 34 & 32 & 2 & 40 & 1 & 13 & 0 \\
\hline Green grapes & 10 & 31 & 25 & 7 & 52 & 0 & 0 & 7 \\
\hline Brussels sprouts & 20 & 29 & 27 & 2 & 39 & 0 & 0 & 11 \\
\hline Scallions & 32 & 29 & 27 & 3 & 35 & 4 & 0 & 0 \\
\hline Green beans & 27 & 25 & 22 & 3 & 42 & 0 & 1 & 5 \\
\hline Orange & 36 & 22 & 7 & 15 & 12 & 11 & 8 & 11 \\
\hline Broccoli & 3 & 22 & 22 & 0 & 49 & 0 & 0 & 27 \\
\hline Apple (red delicious) & 22 & 20 & 19 & 1 & 23 & 13 & 5 & 17 \\
\hline Mango & 52 & 18 & 2 & 16 & 4 & 6 & 0 & 20 \\
\hline Green lettuce & 33 & 15 & 15 & 0 & 36 & 0 & 16 & 0 \\
\hline Tomato juice & 0 & 13 & 11 & 2 & 2 & 57 & 12 & 16 \\
\hline Peach & 20 & 13 & 5 & 8 & 8 & 0 & 10 & 50 \\
\hline Yellow pepper & 86 & 12 & 12 & 0 & 1 & 0 & 1 & 0 \\
\hline Nectarine & 18 & 11 & 6 & 6 & 23 & 0 & 0 & 48 \\
\hline Red pepper & 56 & 7 & 7 & 0 & 2 & 8 & 24 & 3 \\
\hline Tomato (fruit) & 0 & 6 & 6 & 0 & 0 & 82 & 0 & 12 \\
\hline Carrots & 0 & 2 & 2 & 0 & 0 & 0 & 43 & 55 \\
\hline Cantaloupe & 9 & 1 & 1 & 0 & 0 & 3 & 0 & 87 \\
\hline Dried apricots & 2 & 1 & 1 & 0 & 9 & 0 & 0 & 87 \\
\hline Green kidney beans & 72 & 0 & 0 & 0 & 28 & 0 & 0 & 0 \\
\hline
\end{tabular}

The content of the major carotenoids are given in mole $\%$. The amounts of the carotenoids were shown in seven major groups, as neoxanthins and violaxanthin (neoxanthin, violaxanthin, and their related isomers, lutein 5, 6 epoxide), lutein, zeaxanthin, cryptoxanthins ( $\alpha$ cryptoxanthin, $\beta$ cryptoxanthins, and related isomers), lycopenes (lycopene and related isomers), $\alpha$ carotene (all trans $\alpha$ carotene and cis isomers), and $\beta$ carotene (all trans $\beta$ carotene and cis isomers). Lutein and zeaxanthin are given combined and as single amounts. The data are sorted by the combined amount of lutein and zeaxanthin. 
the mobile phase two solvents were prepared. Solvent A consisted of acetonitrile/methanol $(85: 15, \mathrm{v} / \mathrm{v})$, with $0.01 \%(\mathrm{w} / \mathrm{v})$ ammonium acetate and pure isopropanol was solvent $\mathrm{B}$. Ammonium acetate was purchased from Baker, Phillipsburg, NJ, USA. Methanol, isopropanol, and acetonitrile were purchased from EM science, Gibbstown, NJ, USA. During the run a mix of $90 \%$ solvent $\mathrm{A}$ and $10 \%$ of solvent $B$ was used. The initial flow rate was set on $0.5 \mathrm{ml} / \mathrm{min}$. At 10 minutes a 5 minute flow gradient ramp was executed, and a final flow rate of $1.2 \mathrm{ml} / \mathrm{min}$ was established. At 22 minutes the flow rate was decreased within a 5 minute ramp to the initial setting. The total time of one run was 27 minutes.

\section{Results}

The content of carotenoids for the various fruits and vegetables is shown in Table 1 . The data are sorted by looking for the highest mole $\%$ of xanthophylls (lutein and zeaxanthin) of total carotenoids. The highest amounts of lutein and zeaxanthin were found in egg yolk (54 mole $\%$ of lutein and 35 mole $\%$ of zeaxanthin), and in maize (corn) ( 60 mole $\%$ of lutein and 25 mole $\%$ of zeaxanthin). In maize we found the highest mole $\%$ of lutein among all fruits and vegetables in our study. Lutein also was also the major carotenoid in kiwi fruit (54 mole\%), red seedless grapes (53 mole\%), zucchini squash (52 mole\%), and pumpkin (50 mole\%). Zeaxanthin was the major carotenoid in orange pepper $(37 \mathrm{~mol} \%)$, which was also the food with the highest percentage of this carotenoid among all fruits and vegetables (Table 1). It is interesting that green pepper has 36 mole $\%$ of lutein and 3 mole $\%$ of zeaxanthin, whereas in orange pepper we find a carotenoid composition with only 8 mole\% lutein, but $37 \mathrm{~mole} \%$ of zeaxanthin. In contrast with the green and orange peppers described above, yellow and red pepper are vegetables with a low amount of lutein ( $12 \mathrm{~mole} \%$ and 7 mole\%) and no zeaxanthin. In carrots, cantaloupe, dried apricots, and green kidney beans almost no lutein and zeaxanthin were found. In green leafy vegetables the amount of lutein in spinach was $47 \mathrm{~mole} \%$, in stalks and leaves of celery 34 mole $\%$, in Brussels sprouts 27 mole $\%$, in scallions 27 mole $\%$, in broccoli 22 mole $\%$, and in green lettuce 15 mole $\%$. The amount of zeaxanthin in these vegetables ranged from 0 to 3 mole $\%$.

\section{Discussion}

Carotenoids have many biological effects, ${ }^{23}$ and can function as antioxidants to protect eye tissues against free radicals. ${ }^{4-6}$ The only source of carotenoids for humans is food, and the carotenoid availability in plasma is critical in long term maintenance of adequate tissue levels. A correlation exists between carotenoid intake and plasma carotenoid concentrations. ${ }^{24}$ However, the individual variability in plasma response to carotenoid intake in humans is large. ${ }^{25}$ The mechanisms providing the transport of carotenoids from intestine to the tissues are not clearly understood. Scita et $a l^{26}$ proposed that the uptake of carotenoids in cul- tured small intestine cells of rats takes place in the absence of any receptor regulation. The postprandial incorporation into lipoproteins could be demonstrated in normolipaemic subjects for $\beta$ carotene by Cornwell et al in 1962. ${ }^{27}$ The transport of the carotenoids in blood, and the distribution to the different tissues is done by lipoproteins. Clevidence and Bieri reported that low density lipoproteins (LDL) carries most of the total carotenoids in plasma, but they also found that individual carotenoids are not uniformly distributed among lipoproteins. ${ }^{28}$ In their population, $67 \%$ of $\beta$ carotene was found in LDL but $53 \%$ of lutein and zeaxanthin was found in high density lipoproteins (HDL). ${ }^{28}$ It might be possible that the retina is able to use this preselection of carotenoids by the lipoproteins to accumulate lutein and zeaxanthin from the plasma carotenoids. Bernstein et al recently found an ocular carotenoid binding protein in the bovine retina, ${ }^{29}$ which could also play a role in humans. The major carotenoids in the human eye are lutein and zeaxanthin, ${ }^{1-3} 30$ and it is not clear yet by which mechanism these carotenoids accumulate in the ocular tissues out of food. However, the amount of macular pigment can be modulated by the diet. ${ }^{7-9} 3132$

Our results match those from a large analytical study of Mangels et $a l^{21}$ where data from a large number of articles on carotenoids in food from 1971 to 1991 were summarised. However, typically the content of lutein and zeaxanthin was reported as a single number, and there is no easy access to information about the content of the individual macular pigments in fruits and vegetables. ${ }^{21}$ The data in Table 1 show that there is a large variation in the amount of lutein and zeaxanthin in fruits and vegetables. Lutein is present in many fruits and vegetables, whereas zeaxanthin is found only in a small number of fruits and vegetables, and in eggs. For example, in maize 85 mole $\%$ of the carotenoids are lutein and zeaxanthin. Interestingly, in most dark green vegetables, such as scallions, green lettuce, celery, spinach, and Brussels sprouts, only traces of zeaxanthin, the most prevalent macular pigment, ${ }^{12} 30$ were found. In our study, the highest amount of zeaxanthin was found in orange pepper, which was not previously analysed.

The highest mole percentage of both lutein and zeaxanthin (89 mole\%) was found in egg yolk. Since eggs have a high cholesterol content, a restricted intake of eggs has been recommended for many years, since cholesterol is a risk factor for coronary artery disease. However, in recent years several studies were published showing that a higher intake of cholesterol through the addition of more eggs in the diet, results not only in an increase of serum cholesterol, but also in an increase of HDL cholesterol. ${ }^{33}{ }^{34}$ Since HDL cholesterol is protective against atherosclerosis, extra egg consumption may not change the risk index for ischaemic heart disease based on the cholesterol levels. ${ }^{33}{ }^{34}$ The consumption of eggs could actually be beneficial in order to obtain a higher intake of lutein and zeaxanthin, and since it has no severe adverse effects on cardiac 
risk factors, the exclusion of eggs from the diet could be reconsidered.

The two studies of the Eye Disease Case Control Study Group in recent years showed a direct relation between the exudative form of ARMD and a decreased plasma level of lutein and zeaxanthin. ${ }^{11}{ }^{12}$ It was found that a diet rich in dark green leafy vegetables could decrease the risk of ARMD. ${ }^{12}$ These data support the hypothesis that a higher intake of lutein and zeaxanthin can prevent this form of ARMD. However, according to our data, this recommendation may be extended to include fruits and vegetables of other colours using Table 1 as a guideline. Recently, Khachik et $a l^{5}$ reported evidence for conversion between lutein and zeaxanthin through several oxidation intermediates, which would suggest that intake of lutein can also raise macular levels of zeaxanthin.

\section{Conclusion}

Our study demonstrated that consumption of fruits and vegetables of various colours would increase dietary intake of lutein and zeaxanthin, and showed that the options are not limited to dark green leafy vegetables, which were previously recommended. In this study no evidence has been produced to show that lutein and zeaxanthin reduce the prevalence of ARMD, and the evidence from other studies is not incontrovertible.

We thank Dr Daniel Gold from the University of Texas Medica Branch, Galveston, and Dr August Deutman from the UniverBranch, Galveston, and Dr August Deutman from the Univer-
sity of Nijmegen, Nijmegen for their helpful comments on this sity of Nijm

FJMGvK was supported by grant from the National Eye Institute, No EY-08818. OS was supported by a grant of the German Academic Exchange Service, DAAD No D/94/20537. Dr van Kuijk is a Research to Prevent Blindness William \& Mary Greve Scholar.

1 Handelman GJ, Dratz EA, Reay CC, et al. Carotenoids in the human macula and whole retina. Invest Ophthalmol Vi Sci 1988;29:850-5

2 Bone RA, Landrum JT, Fernandez L, et al. Analysis of the macular pigment by HPLC: retinal distribution and age study. Invest Ophthalmol Vis Sci 1988;29:843-9.

3 Snodderly DM, Handelman GJ, Adler AJ. Distribution of individual macular pigment carotenoids in central retina of macaque and squirrel monkeys. Invest Ophthalmol Vis Sci 1991;32:268-79.

4 Gerster H. Review: Antioxidant protection of the ageing macula. Age Ageing 1991;20:60-9.

macula. Age Ageing 1991;20:60-9. ing approach to reducing the risk of coronary heart disease, ing approach to reducing the risk of coronary heart disease, 50 .

6 Young RW. Solar radiation and age-related macular degeneration. Surv Ophthalmol 1988;32:252-69.

Hammond BR, Fuld K, Snodderly DM. Iris color an macular pigment density. Exp Eye Res 1996;62:293-7.

8 Landrum JT, Bone RA, Mark HJ, et al. A one year study of the macular pigment: The effect of 140 days of a lutein supplement. Exp Eye Res 1997;64:311-16.

9 Hammond BR, Johnson EJ, Russell RM, et al. Dietary modification of human macular pigment density. Invest Ophthalmol Vis Sci 1997;38:1795-801.

10 Jacques PF, Chylack LT Jr. Epidemiologic evidence of a role for the antioxidant vitamins and carotenoids in cataract prevention. Am f Clin Nutr 1991;53:352S-5S.
11 Eye Disease Case-Control Study Group. Antioxidant status and neovascular age-related macular degeneration. Arch Ophthalmol 1993;111:104-9.

12 Seddon JM, Ajani UA, Sperduto RD, et al. Dietary carotenoids, vitamins $\mathrm{A}, \mathrm{C}$, and $\mathrm{E}$, and advanced age-related macular degeneration. Eye Disease Case-Control Study Group. ҰAMA 1994;272:1413-20

13 West SK, Vitale S, Hallfrisch J, et al. Are antioxidants or supplements protective for age-related macular degeneration? Arch Ophthalmol 1994;112:222-7.

14 Mares-Perlman JA, Brady WE, Klein R, et al. Serum antioxidants and age-related macular degeneration in population-based case-control study. Arch Ophthalmol 1995;113:1518-23.

15 Snodderly DM. Evidence for protection against age-related macular degeneration by carotenoids and antioxidant vitamins. Am f Clin Nutr 1995;62 (suppl): 1448S-61S.

16 Landrum JT, Bone RA, Kilburn MD. The macular pigment: A possible role in protection from age related macular degeneration. Adv Pharmacol 1997;38:537-56.

17 Khachik F, Beecher GR. Application of a c-45-b-carotene as an internal standard for the quantification of carotenoids in yellow/orange vegetables by liquid chromatography. 7 Agric Food Chem 1987;35:732-8.

18 Khachik F, Beecher GR. Separation and identification of carotenoids and carotenol fatty acid esters in some squash products by liquid chromatography. 1. Quantification of carotenoids and related esters by HPLC. $\mathcal{F}$ Agric Food Chem 1988;36:929-37.

19 Khachik F, Beecher GR, Lusby WR. Separation, identification, and quantification of the major carotenoids in extracts of apricots, peaches, cantaloupe, and pink grapefruit by liqof apricots, peaches, cantaloupe, and pink graperruit by liq-

20 Ong ASH, Tee ES. Natural sources of carotenoids from plants and oils. In: Packer L, ed. Methods in enzymology. London: Academic Press, 1992;213:142-67.

21 Mangels AR, Holden JM, Beecher GR, et al. Carotenoid content of fruits and vegetables: an evaluation of analytic data. F Am Diet Assoc 1993;93:284-96. (Published erratum appears in f Am Diet Assoc 1993;93:527.)

22 Sommerburg O, Zang L, van Kuijk FJGM. Simultaneous detection of carotenoids and vitamin $\mathrm{E}$ in human plasma. $\mathcal{f}$ Chromatogr 1997;695:209-15.

23 Krinsky NI. Actions of carotenoids in biological systems. Annu Rev Nutr 1993;13:561-87.

24 Forman MR, Lanza E, Yong LC, et al. The correlation between two dietary assessments of carotenoid intake and plasma carotenoid concentrations: application of a carotenoid food-composition database. Am 7 Clin Nutr 1993;58. 519-24.

25 Micozzi MS. Evaluation of carotenoid intake. Methods Enzymol 1993;214:17-21.

26 Scita G, Aponte GW, Wolf G. Uptake and cleavage of betacarotene by cultures of rat small intestinal cells and human lung fibroblasts. Methods Enzymol 1993;214:21-32.

27 Cornwell DG, Kruger FA, Robinson HB. Studies on the absorption of beta-carotene and the distribution of total carotenoid in human serum lipoproteins after oral administration. $\mathcal{F}$ Lipid Res 1962;3:65-70.

28 Clevidence BA, Bieri JG. Association of carotenoids with human plasma lipoproteins. Methods Enzymol 1993;214: 33-46.

29 Bernstein PS, Tsong ED, Rando RR. Isolation of a carotenoid binding protein from bovine retina. Invest Ophthalmol Vis Sci 1995;36:S5(Abstract)

30 Yeum KJ, Taylor A, Guangwen T, et al. Measurement of carotenoids, retinols, and tocopherols in human lenses. Invest Ophthalmol Vis Sci 1996;36:2756-61.

31 Malinow MR, Feeney-Burns L, Peterson LH, et al. Diet-related macular anomalies in monkeys. Invest Ophthalmol Vis Sci 1980;19:857-63.

32 Hammond BR, Fuld K, Currancelentano J. Macular pigment density in monocygotic twins. Invest Ophthalmol Vis Sci 1995;36:2531-41.

33 Schnohr P, Thomsen OO, Riis Hansen P, et al. Egg consumption and high-density-lipoprotein cholesterol. $\mathscr{f}$ Int Med 1994;235:249-51.

34 Ginsberg HN, Karmally W, Siddiqui M, et al. A doseresponse study of the effects of dietary cholesterol on fasthealthy young men. Arterioscler Thromb 1994;14:576-86.

35 Khachik F, Bernstein PS, Garland DL. Identification of lutein and zeaxanthin oxidation products in human and monkey retinas. Invest Ophthalmol Vis Sci 1997;38:180211 